\title{
Genitalidad e (im)potencia del pensamiento: Heidegger, Deleuze, Agamben
}

\section{Sebastián Pimentel}

Pontificia Universidad Católica del Perú

Resumen: El presente artículo da cuenta de cómo en Heidegger, Deleuze y Agamben las concepciones sobre el pensar, por un lado, y la actividad filosófica, por otro, lejos de ser indistintas la una respecto de la otra, implican diferencias fundamentales. Sin embargo, nuestra lectura de los tres autores también propone descubrir una filiación común referida a la contraposición entre "doxa" y "pensamiento": las de Heidegger, Deleuze y Agamben constituyen tres vías por las que podemos comprender el "nacimiento" o "surgimiento" del pensamiento, experiencia o actividad que no debe suponerse como efectuación posible desde el ámbito de la comunicación o re-presentación. Todas estas consideraciones confluyen, finalmente, en la calidad sutil del pensamiento como "potencia" liminar que, de acuerdo a cada autor, debe comprenderse también en su calidad paradójica de "impotencia", calidad mucho más cercana a una experiencia de la in-corporación como acontecimiento (Heidegger); al momento presupuesto y no discursivo -y a la vez constituyente- de la "creación" ya sea filosófica, artística o científica (Deleuze); o al de la pura fruición de la potencia, como experiencia de una especie de "privación" tan positiva como ilimitada y que se sustrae a cualquier "función" (Agamben).

Palabras clave: Heidegger, Deleuze, Agamben, pensamiento, filosofía

Abstract: This paper reports how according to Heidegger, Deleuze, and Agamben, both the notion of thinking and of philosophical activity, far from meaning the same, involve fundamental differences. However, our reading of the three authors also proposes to discover a common affiliation related to the contrast between "doxa" and "thinking"; Heidegger's, Deleuze's and Agamben's are three ways by which we can understand the "birth" or "emergence" of thinking as an experience or activity that should not be understood as stemming from the field of communication or re-presentation. All 
these considerations converge finally in the subtle quality of thought as liminal "power" that, according to each author, must also be understood in its paradoxical quality of "impotence", quality much closer to the experience of in-corporation as an event (Heidegger); to the pre-supposed, non-discursive moment -and simultaneously constituent- of either philosophical, artistic, or scientific "creation" (Deleuze); or to the pure enjoyment of power, as the experience of a type of "deprivation", both positive and unlimited, as well as eluding any "function" (Agamben).

Keywords: Heidegger, Deleuze, Agamben, thought, philosophy

Y esto, también, es un engaño; pretender que en algún punto remoto del pasado el hombre comenzó a pensar. El hombre ni siquiera ha empezado a pensar.

Henry Miller, "El tiempo de los asesinos"

Uno de los temas más recurrentes en la obra de Deleuze, desde sus obras tempranas hasta sus obras tardías, fue el de la naturaleza del pensamiento, su posibilidad o imposibilidad, y la relación de este con una filosofía del acontecimiento que no cesaba de re-configurarse en cada uno de sus libros. El tema resultaba particularmente intrigante ya desde Diferencia y repetición, que puede considerarse como una de las primeras y más contundentes exposiciones de una filosofía propia y original. Allí decía Deleuze: "Pensar es crear, y (...) crear es, ante todo, engendrar 'pensamiento' en el pensamiento. Por eso Artaud opone en el pensamiento la genitalidad al innatismo, pero también a la reminiscencia (...)"214. En esta misma obra, ya había dicho Deleuze: "lo que el pensamiento está forzado a pensar es también su hundimiento central, su fisura, su propio 'no poder' natural que se confunde con la mayor potencia"215. El pensamiento, entonces, es un drama que, como veremos más adelante, tiene que ver con una fractura, con el fracaso del sentido común en un encuentro con "el afuera" (dehors), es decir, con un fracaso de la re-presentación. Pero lo más interesante es que este derrumbe, como condición del nacimiento del pensamiento, es también la experiencia de su imposibilidad o "impoder".

214 Deleuze, G., Diferencia y repetición, Buenos Aires: Amorrortu, 2002, p. 227.

215 Ibid., p. 226. 
Por lo tanto, surge una pregunta central que no dejará de ser planteada: ien qué sentido la impotencia del pensamiento es, también, la experiencia de su más alta potencia?

Lo que queremos con este ensayo es examinar el rol de esta pregunta sobre el pensamiento y lo que él implica para la filosofía de tres autores estrechamente vinculados no solo por esta pregunta, sino también por su forma de abordarla. Finalmente, detrás de "la genitalidad" o "impotencia del pensamiento", hay otros temas que están en juego: el sentido del ejercicio filosófico y su naturaleza; el rechazo del mundo de la re-presentación, la técnica o la opinión (doxa); y, finalmente, el vínculo con la vida. Estos temas nos permitirán abordar algunos objetivos que acercan y diferencian, a la vez, las obras de Heidegger, Deleuze y Agamben.

\section{§ 1. Heidegger}

En el caso de Heidegger, nos enfrentamos, quizá, al primer filósofo que plantea la pregunta por el pensamiento en términos de su efectuación aún no cumplida y "por venir", de su propia imposibilidad. La pregunta por esta imposibilidad es también la pregunta por una necesidad, por la urgencia de hacer posible el pensamiento, de "hacerlo nacer" (en ese sentido es que hablamos de "genitalidad", tomando prestada la palabra de Deleuze). Es decir, el pensamiento no es innato, ni tampoco una cuestión de "volver la mirada correctamente" a ideas pre-existentes, ni una cuestión de rememoración platónica. Pero, si se trata de hacer posible el pensamiento, surge la pregunta: ihacer nacer el pensamiento desde dónde?

Estas preguntas son las que circundan la advertencia de que todavía no pensamos, y de que quizá nunca hayamos pensado. Es decir, Heidegger regresa a la Universidad de Friburgo, en 195I, para plantear una pregunta en un lenguaje más sencillo y menos académico que el que animó Ser y tiempo (1927), aunque con una densidad no menor ni con alcances menos profundos. Todo parte de una consideración inquietante y hasta estremecedora: quizá tengamos la capacidad para pensar, pero eso no significa que pensemos efectivamente $\circ$ que hayamos pensado siquiera alguna vez. Sin embargo, si es que todavía no pensamos, surge la pregunta por la naturaleza del pensamiento y su condición 
de posibilidad. ¿Qué significa, pues, en términos ya propiamente "éticos", esta conciencia del no-poder-pensar, una necesidad de pensar como aprendizaje que debe emprenderse desde el no-pensamiento? Por último, en simultáneo, surge la pregunta por la relación entre la actividad del pensamiento y su diferencia respecto a la actividad filosófica: ipensar y "estudiar filosofía" son lo mismo? ¿En qué sentido?

Estas preguntas hay que situarlas en el decurso de la obra de Heidegger. Los seminarios reunidos bajo el título ¿Qué significa pensar? fueron impartidos entre 195I-1952, los primeros que dictó, como se dijo líneas arriba, tras su reincorporación a la Universidad de Friburgo, ya terminada la Segunda Guerra Mundial. Podemos decir, también, que se consolida una segunda etapa en su filosofía: la etapa de "pensar el Ser" deja atrás a la de "estudiar el olvido del ser" -en la Historia de la metafísica ${ }^{216}$. Del "Dasein" y su proyecto de autenticidad, hemos pasado al "hombre" y su imposibilidad de pensar. $Y$ ante ambos, la diferencia ontológica, el tiempo como dimensión que oculta y devela el Ser del ente. Como es sabido, para el filósofo alemán nuestro olvido del Ser se explicaba en función de una metafísica de la re-presentación, de la cosificación. Re-presentar para disponer, re-presentar para un saber técnico-científico es la consecuencia de una Historia de la metafísica que nos lleva hacia una consumación nihilista. En ese sentido, también, es que debe comprenderse que "razonar", entendida la palabra como facultad de entendimiento re-presentativo, proposicional, lógico o de orden matemático, no sería, para Heidegger, propiamente "pensar"217.

Pero el de Heidegger no es un movimiento artificial o arbitrario. Podríamos decir que, de alguna manera, el "esfuerzo por pensar"-yel "pensar" como tema

216 M. Berciano resume asíla temprana empresa heideggeriana todavía jalonada por un interés histórico: "Una primera etapa del pensamiento de Heidegger, (...) en el contexto de un espíritu vital e histórico, centra por entonces su reflexión en el tema de la vida fáctica, concreta, real. El sentido del ser ha de determinarse a partir de esta vida, que se desarrolla en situaciones históricas concretas". Y luego: "La reflexión sobre la vida fáctica y en sus situaciones históricas concretas le hizo, pues, ver a Heidegger las deficiencias en la metafísica. ¿Se podrá tal vez suplir las deficiencias (...) mediante una nueva reflexión que afronte la dimensión del tiempo y de lo histórico en el ser? Heidegger intenta dar una respuesta en (...) Ser y tiempo" (Berciano, M., Técnica moderna y formas de pensamiento. Su relación en Martin Heidegger, Salamanca: Universidad de Salamanca, 1982, p. 22).

217 Cf. Heidegger, M., ¿Qué significa pensar?, Madrid: Trotta, 2005, p. 53. 
mismo del pensamiento-es ahora, también, lo propiamente "problemático" de nuestro tiempo, lo que debe ser pensado. Porque más que conceptualizar la "diferencia ontológica" o de "olvidar al Ser", llegamos al punto en que la advertencia de ese olvido -y el hecho de que seamos conscientes de que hemos olvidado al Ser-nos pone ante una nueva circunstancia: simplemente, el "olvido" del Ser no debe ser solo "postulado". El Ser, como lo no-óntico, como lo que se oculta y devela en el ente, debe ser pensado efectivamente. Pero, iserá eso posible? Heidegger subraya, en efecto, que: "Lo que más merece pensarse en nuestro tiempo problemático es el hecho de que no pensamos"218. Comenta que el interés por la filosofía no asegura, en lo más mínimo, una actividad o efectuación del pensamiento. Y continuación sostiene: “(...) el hecho mismo de que durante años nos entreguemos con auténtico empeño al estudio de los tratados y escritos de los grandes pensadores, todavía no nos concede la garantía de que nosotros mismos pensemos o estemos dispuestos a pensar. Por el contrario: la ocupación con la filosofía puede simularnos muy pertinazmente la apariencia de que pensamos puesto que 'filosofamos' sin cesar"219.

La filosofía, como disciplina, no engendra al pensamiento. Pensar, pues, no es sinónimo de estudiar la historia de la filosofía-como sí, en cambio, hubiera sido condición de posibilidad para Hegel. Es más, podría incluso decirse que, para "el primer" Heidegger, el proyecto del estudio de la historia de la metafísica como "consumación" y desarrollo del saber técnico-científico y, en fin, como "olvido del Ser", tenía una impronta fundacional y por ello mismo teleológica, de inspiración hegeliana.

Entonces, podríamos decir que el hallazgo del concepto "Ser" (Sein) y la dimensión existencial que supone esta categoría, gracias al análisis de la temporeidad del ente que practica Heidegger en Ser y tiempo, se hace insuficiente. Heidegger parece arribar, en ¿Qué significa pensar?, a otro suelo. Aunque su estudio de la pregunta por el "pensar" todavía admita eventualmente una vuelta al origen, a Grecia y los presocráticos, así como una discusión con algunos filósofos modernos o contemporáneos (Nietzsche), no se trata ya de una Historia. Estos seminarios parecen volver la mirada hacia el pasado, pero siempre para llegar a un punto donde el rechazo de la re-presentación 
técnico-científica y el "saber" que este supone también tienen que ver con el rechazo de un estudio histórico de la filosofía.

En efecto, Heidegger parece fluctuar entre un rastreo etimológico de la palabra "pensar" y un señalamiento de la experiencia que no re-presenta, una experiencia del cuerpo que se enfrenta a lo que se le presenta, a su "afuera", como veremos más adelante. ¿Se tratará, entonces, de rechazar "la imagen dogmática del pensamiento" 220 , como quería Deleuze? De hecho, el mismo Deleuze señala con admiración, en repetidas veces, a Heidegger como uno de los primeros en "descubrir" la impotencia del pensamiento como su más alta verdad ${ }^{221}$. Definitivamente, a pesar de sus diferencias, el último Heidegger se acercó bastante - por lo menos en algunos puntos- a Deleuze. Dice Heidegger: “(...) lo que merece pensarse, lo que nos da que pensar, de ninguna manera está fijado, no está implantado por nosotros, no somos nosotros los que lo hemos puesto ante nuestros ojos, los que lo hemos re-presentado. Lo que más da que pensar de suyo, lo más merecedor de pensarse, según la afirmación mencionada, es el hecho de que nosotros todavía no pensamos"222.

Guiándonos por la interpretación de Modesto Berciano, para Heidegger “'representable' (Vor-stellbar) significa: accesible en el opinar y calcular, relegando así lo problemático"223. De la doxa a la técnica, Heidegger emprende su nueva filosofía del "pensar" desde la crítica a la cultura occidental como proyecto técnico-científico, como actividad de re-cognición de lo Mismo (en tanto "eternamente presente"). Lo "problemático", en ese sentido, se da en la confrontación con lo que escapa a la re-presentación y que Heidegger llamaría experiencia del "acontecimiento" (Ereignis). En ese sentido es que también surge la pregunta por el pensar: ila experiencia del acontecimiento sería la experiencia del pensar?224

220 Deleuze acuña la categoría "imagen dogmática del pensamiento" para referirse a un pensamiento entendido como re-cognición de Lo Mismo. Sobre este tema, ver el capítulo 3 de Diferencia y repetición, pp. 20I-255. También puede verse: Deleuze, G., Nietzsche y la filosofía, Barcelona: Anagrama, 2000, p. 146.

22I Cf. Deleuze, G., Diferencia y repetición, pp. 222-223.

222 Heidegger, M., ¿Qué significa pensar?, pp. 17-I8. Las cursivas son nuestras.

223 Berciano, M., La crítica de Heidegger al pensar occidental, Salamanca: Universidad Pontificia Salamanca, 1990, p. 174.

224 Cf. Heidegger, M., Aportes a la filosofía. Acerca del evento, Buenos Aires, Biblos, 20II, pp. 82-83. Sobre este tema, véase también: Berciano, M., Superación de la metafísica en Martin 
Hay que recordar que la pregunta por el pensar estaba antecedida por sus ensayos sobre "El origen de la obra de arte" o "Hölderlin y la esencia de la poesía", ambos escritos en la década del treinta. En esa década es que el concepto de "Ereignis" comienza a adquirir una relevancia fundamental en su filosofía. Es decir, el concepto de "acontecimiento", íntimamente relacionado al arte y al lenguaje $\mathrm{e}^{225}$, va a terminar por configurar un horizonte filosófico que tiene, también, resonancias importantes con la obra de Gilles Deleuze.

De lo que se trata, finalmente, es de re-incorporar al pensamiento en el acontecimiento del arte. Devolverle un cuerpo al pensamiento es hacer, del cuerpo, el escenario del acontecimiento, y de la sensibilidad, la puerta de entrada. $Y$ es que, más allá de un ejercicio especulativo, de un estudio dialéctico o una deducción formal de pensamientos, Heidegger reclama un acontecimiento -que el arte hace posible- ante el fracaso de la re-cognición - la representación. En ese sentido, Heidegger y Deleuze confluyen. Sin embargo, ¿Heidegger lleva hasta las últimas consecuencias un enfrentamiento con el "afuera" de la representación? ¿Se zambulle, en ese sentido, en el terreno estético o artístico, con la determinación con la que lo hará Deleuze en sus estudios de la literatura, la pintura o el cine?

El punto en que tenemos que concluir este breve sobrevuelo de la filosofía de Heidegger recae en la pregunta: ¿Heidegger pudo intuir "un pensamiento del afuera"? Dice el autor en ¿Qué significa pensar?: "Nosotros estamos fuera de la ciencia. Y en lugar de estar en ella nos encontramos, por ejemplo, ante un árbol en flor, y también el árbol está ante nosotros. Él se nos presenta. El árbol y nosotros nos presentamos recíprocamente, y lo hacemos por el hecho de que el árbol está ahí y nosotros estamos frente a él. El árbol y nosotros somos en la relación recíproca, puestos el uno ante el otro. Por tanto, en este presentar no se trata de 'representaciones' que revolotean en nuestra cabeza. Detengámonos aquí concentradamente un instante, a la manera como aspiramos con profundidad antes y después de un salto. En efecto, ahora hemos

Heidegger, Oviedo: Universidad de Oviedo, 1991, pp. 292-308, 331-338.

225 "La verdad acaece (...) especialmente en el lenguaje poético, en el pensar, en el arte (...). Estos modos o estos lugares del acaecer de la verdad son vistos por Heidegger como más auténticos que la metafísica occidental, la ciencia o la técnica fundadas en ella" (Berciano, M., La crítica de Heidegger al pensar occidental, p. 183). Ver también el fundamental trabajo de Heidegger citado anteriormente (Aportes a la filosofía. Acerca del evento). 
saltado, hemos salido del círculo usual de las ciencias e incluso, como veremos, de la filosofía. Pero, ¿a dónde hemos saltado? ¿Quizá a un abismo? iNo! Más bien a un suelo. ¿A uno? iNo! Más bien al suelo en el que vivimos y morimos, en el que no nos andamos con engaños. Es una cosa sorprendente e incluso terrible que hayamos de saltar al suelo en el que propiamente estamos. Si se requiere algo tan curioso como este salto, ha tenido que suceder algo que da que pensar"226. Heidegger se sorprende y se alarma ante el olvido de la experiencia de "estar en el suelo en el que propiamente estamos", ante la enajenación que ya se ha hecho normal, que nos saca de nuestra finitud, de nuestro cuerpo, del suelo al que apela en el fragmento citado. Definitivamente, y como se puede ver en esas líneas, hay una serie de exigencias éticas que están detrás de este "salto". Para Heidegger, se trata de dejar de estar "fuera de nosotros", es decir, dejar de estar alienados por una razón técnica, lógica o especulativa (que es, finalmente, la que "puede más" en términos de manipulación y producción industrial, de "Ge-Stell", de poder, de transformación o administración de la vida y la muerte).

Heidegger, al pedirnos que pensemos desde nuestro cuerpo, quizá esté siendo, a pesar suyo, menos místico y más estético, menos inefable y más concreto, menos lingüístico y más cinematográfico. En efecto, dice Heidegger que, al estar frente al árbol en flor, "hemos saltado, hemos salido del círculo usual de las ciencias e incluso, como veremos, de la filosofía". Hemos saltado "al suelo en que vivimos y morimos", "en el que no nos vienen con engaños". El suelo en el que "vivimos y morimos" es el de la "temporeidad", el de nuestro serpara-la-muerte, el de la finitud que experimentamos gracias a la conciencia del tiempo. Y si en este suelo de la finitud y del tiempo "no nos vienen con engaños", es porque ya hemos salido de la metafísica del ente como eternamente presente. Pero, en última instancia, y más allá de alejarnos de un saber especulativo o técnico que para Heidegger también puede ser una forma de piedad y de cuidado de la naturaleza o physis, icuál es la importancia de que el pensamiento deje de ser formal y se re-incorpore? ¿A qué se debe ese reclamo? ¿Cuál es la potencia de ese pensamiento del cuerpo?

226 Heidegger, M., ¿Qué significa pensar?, pp. 34-35. Las cursivas son nuestras. 
Es sabido que a Heidegger no le gustaba el cine (lo consideraba como un medio de comunicación de doxa, como una perversión más de la técnica) $)^{227}$. Sin embargo, a pesar suyo, nos atrevemos a afirmar que Heidegger ya intuía al cine moderno. Quién lo diría. Pese a que suene a herejía, "el suelo al que caemos", por lo menos desde este extraño y bello extracto de ¿Qué significa pensar?, podemos identificarlo con la experiencia que nos da el arte como “imagen-tiempo", para usar el concepto de Deleuze ${ }^{228}$. En ese sentido, como explicaremos más adelante, Heidegger está cerca de Tarkovsky, de Bela Tarr o de Sokurov.

Diremos, entonces, que las palabras de Heidegger nos colocan en una situación de presentación, no de re-presentación, una situación de presentación efectuada como tiempo puro y, en ese sentido, como enfrentamiento con "el afuera" o como "acontecimiento", para decirlo con palabras de Heidegger. El árbol de Heidegger solo "vive". Accedemos a una imagen sin correlato sensomotriz porque no hay una relación de utilidad ni de persecución de un fin. No vemos-para-actuar. En este caso, vemos-para-ver. En ese sentido, también, es que podemos hablar de una "imagen-tiempo", donde el tiempo ya no se subordina al movimiento (como en el cine de acción). Con la "imagen-tiempo" no hay acción, sino un acceso directo a la "temporeidad", donde el temblor de la sombra y el viento hacen sentir un flujo o plano de tiempo como dimensión "trascendente" (del plano de lo "óntico"), hacen sentir una precariedad de lo que es y un juego de ocultamiento y desocultamiento como verdad del mundo. Tal como en Tarkovsky o en Sokurov ${ }^{229}$. Ahora bien, es cierto que este ejemplo del árbol puede ser tomado como acontecimiento no necesariamente "cinematográfico". Sin embargo, si mencionamos al cine, es porque el cine, como arte de las "imágenes-tiempo", "conserva” el acontecimiento, de acuerdo a Deleuze $^{230}$. En ese sentido, como también reivindicaba Heidegger, es el arte

227 Sobre Heidegger y el cine, véase el comentario crítico de Luna Alcoba, M., Cine y televisión como "Ideología". Aspectos de la crítica de Adorno a la cultura de masas (Post- scriptum a Mundo Imagen), en: Filosofía sin concesiones (https://sites.google.com/site/filosofiasinconcesiones/home), 2009. Fecha de consulta: I de setiembre de 2015.

228 Cf. Deleuze, G., La imagen-tiempo. Estudios sobre cine 2, Barcelona: Paidós, 1996.

229 Para un cotejo de este aspecto "heideggeriano" del cine de Alexander Sokurov, véase por ejemplo nuestro ensayo sobre el filme "Madre e hijo" en: Imagen y mundo. Ensayos sobre cine moderno, Lima: El Nocedal, 2008, pp. 25-43. (cine moderno), supone un paso de un cine que tiene como modelo a las categorías temporales 
el que nos llamaría a pensar. Por eso es que, también con Heidegger, la pregunta por el pensar desemboca naturalmente en el pensamiento del arte. En efecto, Deleuze y Heidegger se unen en cuanto a la posibilidad de engendrar el pensamiento en un "des-hacimiento" del sujeto y de la re-presentación, que significa hacerlo nacer en la experiencia del arte.

\section{§ 2. Deleuze}

Como dijimos al inicio de este artículo, el pensamiento, para Deleuze, debe ser engendrado. Y si el pensamiento debe ser engendrado, debe ser engendrado en sí mismo. El pensamiento no pre-existe. Debe surgir desde su propio seno, desde su impoder, desde su impotencia. Para ello, primero debe acontecer el fracaso o derrumbe de la re-presentación. Debe acontecer una crisis, un drama, una pasión. La perspectiva cambia, en relación a Heidegger. Ya no se trata de un simple "salto" al suelo de la presencia y del afuera, como en el ejemplo de la situación frente al árbol en flor de ¿Qué significa pensar? Este "salto", para Deleuze, es una catástrofe y, a la vez, una revelación.

Para Deleuze, en confrontación con Heidegger esta vez, no se trata de prepararnos para "esperar" el pensamiento del Ser. Ya no hay metáforas de "donación" y de "espera" de lo que debe ser pensado 231 . El hombre frugal de Heidegger que busca el regalo del Ser en el bosque es ahora, con Deleuze, un ciudadano asaltado por un encuentro inesperado en la ciudad. No se trata de esperar el acontecimiento “donador": el acontecimiento es ahora un golpe, un choque, una situación inesperada pero necesaria, y necesaria por inesperada: un encuentro que nos fuerza a pensar. Pero, ¿desde dónde nos encontramos con lo que derrumba nuestros esquemas de re-cognición (doxa)? Pues desde

"históricas", hacia un modelo diferente, uno que más bien toma las categorías temporales del devenir y el acontecimiento. Cf. Marrati, Paola, Gilles Deleuze. Cine y filosofía, Buenos Aires: Nueva Visión, 2004, p. 7I. Sin embargo, habría que acotar en este punto que las grandes películas de la "imagen-movimiento" suponen, desde el momento en que también son "arte", una puesta en crisis de los esquemas de re-presentación (doxa) y, en ese sentido implican, también, un propio pensamiento. Habría, también, que postular con el cine clásico un "afuera de la representación" que, sin embargo, tiene determinaciones menos "directas". Sobre este tema, ver Deleuze, G., La imagen-tiempo. Estudios sobre cine 2, p. 239.

231 "iEs capaz el pensar de salir a recibir este don,... para confiarlo... en un decir, al hablar originario del lenguaje?” (Heidegger, M., ¿Qué significa pensar?, p. 20I). 
nuestro cuerpo. En Deleuze, como en el último Heidegger, el cuerpo es pri$m^{m e r 0^{232}}$. Es desde la sensibilidad de nuestro cuerpo que nos topamos con lo que no podemos re-conocer ni re-presentar.

Entonces, icon qué se encuentra el cuerpo? El cuerpo se encuentra con el signo, se encuentra con signos. Como en Heidegger cuando habla de la obra de arte o como en el ejemplo de la presencia del árbol en flor, cuando habla de una situación que deja de ser "mundana" desde el momento en que lleva implícitas características de una experiencia extra-ordinaria, virtual experiencia de la obra de arte, o virtual película de la "imagen-tiempo". En Heidegger y Deleuze es difícil distinguir, a veces, cuándo hablamos de un "evento" o "acontecimiento" como experiencia fugaz -como presentimiento o "destello"- y cuándo de un evento conservado en la obra de arte -es decir, un evento hecho "monumento". En Proust y los signos, por ejemplo, el artista Proust es el pensador que rivaliza con el filósofo. Allí, dice Deleuze que "La creación, como la génesis del acto de pensar, parte siempre de los signos". Y "La obra de arte nace de los signos tanto como ella los hace nacer..."233. Deleuze hará, luego, algunas variaciones respecto a la naturaleza del signo, pero se mantendrá la posición fundamental del signo como "lo que fuerza a pensar" 234 .

Ahora bien, el punto que nos interesa en esta filosofía del signo es que este signo no es, de ningún modo, un código. Por el contrario, el lenguaje como información, como código, corresponderá al orden de las consignas y de la doxa, al orden del poder (como atestiguan los dos volúmenes de "Capitalismo y esquizofrenia”, el trabajo con Guattari) ${ }^{235}$. El signo que engendra al pensamiento, a través de la sensibilidad del cuerpo, es, como dice Zourabichvili comentando a Deleuze, ya no una consigna o un cliché (una orden que se nos repite en el dominio de lo Mismo), sino "el índice de una fuerza ejercida sobre el pensamiento desde el exterior" ${ }^{236}$. Estamos, pues, lejos del código

232 Sobre este tema, confróntese el artículo de Arnaud Villani "De la estética a la estética: Deleuze y la cuestión del arte”, en: Beaulieu, A. (coord.), Deleuze y su herencia filosófica, Madrid: Campo de Ideas, 2007, pp. 81-97.

233 Deleuze, G., Proust y los signos, Barcelona: Anagrama, 1995, p. I8I.

234 Deleuze, G., Diferencia y repetición, p. 215.

235 Cf. Deleuze, G. y Félix Guattari, Mil mesetas. Capitalismo y esquizofrenia, Madrid: Pretextos, 2004, capítulo 4, pp. 8I-II6.

236 Zourabichvili, F., Deleuze. Una filosofía del acontecimiento, Buenos Aires: Amorrortu, 2004, p. 59. 
claro y distinto, que correspondería al mundo de la opinión, al sistema de creencias y de la experiencia como sentido común. El sentido común fracasa porque, en lugar de la información y del código o cliché de la comunicación (pura re-presentación), "algo se distingue". Es decir, lejos de re-conocer lo Mismo, nos chocamos con "el afuera", y en ese sentido algo se distingue. Algo se hace signo y se distingue como envuelto, implicado: "distinto oscuro" ${ }^{237}$. EI signo hace surgir, así, el pensamiento, engendra al pensamiento en el seno de su propia imposibilidad, de su choque con el afuera, y lo obliga a crearse como diferencia en el recorrido de un problema. Dice Zourabichvili: "Hay problema y sentido en función de un signo que el pensamiento encuentra y que fractura la unidad de lo dado, introduciendo una diferencia de punto de vista"238.

Este signo "distinto oscuro" es el que "afecta" (en lugar del código claro y distinto, que solo da órdenes y/o comunica). $Y$ todo se explica ya como una relación de "fuerzas", un poder de afectar y de ser afectado -en esta senda, Deleuze actualiza la tradición de Spinoza y Nietzsche. Pero ser afectado parte de una distinción en el afuera. Hablamos, entonces, de lo distinto-oscuro como de un afuera-en-el-signo. La crisis del pensamiento, entonces, supone la captación de los signos, siempre envueltos y embrollados en la forma de un problema, el cambio de un punto de vista. Dice Deleuze: "Los problemas (...) emanan de imperativos de aventura o de acontecimientos que se presentan como preguntas. (...) Los imperativos en forma de preguntas significan, por consiguiente, mi mayor impotencia, pero también ese punto del que Maurice Blanchot habla sin cesar, ese punto aleatorio, original, ciego, acéfalo, afásico, que designa 'la imposibilidad de pensar que es el pensamiento', y que se desarrolla en la obra como problema, y donde el 'no poder' se transmuta en potencia" ${ }^{239}$.

Pongamos el caso del cine. En el cine, de acuerdo a Deleuze, "el afuera" también tiene un lugar preeminente en el caso de la "imagen-tiempo". Lo vimos en el último Heidegger, si es que aceptábamos su ejemplo de "acontecimiento" como pre-figuración de un cine del tiempo. En efecto, en el caso del cine moderno, "el afuera" se instala desde el principio entre las junturas de las

237 Cf. Deleuze, G., Diferencia y repetición, p. 226. Sobre el tema del pensamiento como fracaso de la representación en Deleuze, véase también: León, Alejandro, "Gilles Deleuze: el pensamiento como pasión”, en: Estudios de Filosofía, Nº 6 (2007), p. 19-35.

238 Zourabichvili, F., op. cit., p. 58.

239 Cf. Deleuze, G., Diferencia y repetición, pp. 298-30I. 
imágenes, de las tomas. Entre imagen e imagen, hay una falta de continuidad, un corte irracional, un vacío que desfonda la imagen permanentemente. Este vacío entre toma y toma, este dislocamiento del esquema sensomotriz, es el que instala el afuera en la imagen. Solo así, diría Deleuze, se tensa nuestra mirada. La falta de continuidad y racionalidad entre imagen e imagen pone el afuera en la imagen, pero también una impotencia positiva del pensamiento. Con los personajes no podemos reaccionar, ni pensar ante las imágenes que ya se han hecho "intolerables" 240 . Y solo al precio de la impotencia del pensamiento, de la imposibilidad de encadenar las imágenes desde un punto de vista motriz, es que experimentamos una captura, una serie de revelaciones nuevas en la imagen, revelaciones que, por la presión del tiempo, hacen indiferente la distinción entre lo material y lo espiritual, lo real y lo imaginario, lo virtual y lo actual: accedemos a imágenes originales que han superado el cliché, imágenes que, tanto por su propia "oscuridad" como por el "afuera" inscrito en ellas, nos llevan a la posibilidad de una creencia inmanente ${ }^{24 !}$.

Finalmente, volviendo a la relación entre Heidegger y Deleuze, queda por apuntar otro tema interesante que ya habíamos mencionado al inicio. Es el par pensamiento - filosofía. ¿Qué es primero, el pensamiento o la filosofía? ¿Qué los distingue, según Heidegger y Deleuze? ¿Cómo se relacionan en ambos autores? En Heidegger, es claro que pasamos de una fase epistemológica e histórica, la de Ser y tiempo -la etapa de la filosofía-, a una etapa ética, estética y de acaecer, la de las tareas del pensar y la obra de arte -la etapa del pensar. ¿Qué pasa en Deleuze? En Deleuze, la relación entre pensamiento y filosofía tiene otras determinaciones. Veíamos que el pensamiento se activa con los signos, signos fugaces de la vida o signos creados, consistentes y conservados en la obra de arte. Sin embargo, ipodemos hablar, como en Heidegger, de un "fin de la filosofía"? Esa pregunta será resuelta en ¿Qué es la filosofía?, donde, lejos de desestimar a la "filosofía" para poder afirmar la urgencia y el problema del "pensar", se tematiza la relación de íntima co-pertenencia del pensamiento con la filosofía, una relación que, esta vez, ya tiene muy poco que ver con el caso Heidegger.

240 Cf. Deleuze, G., La imagen-tiempo. Estudios sobre cine 2, p. 227. 
Para Deleuze, la filosofía -así como el arte y la ciencia- es un constructivismo y debe definirse como una "creación de conceptos". Si el arte crea un consolidado de "perceptos" y "afectos", si la ciencia crea sistemas discursivos a partir de "funciones", la filosofía crea "conceptos"242. Y el pensamiento no es un dominio exclusivo de ninguno de los tres. La filosofía, el arte y la ciencia, como actividades creadoras, se contraponen a la "doxa". Y en tanto creadoras, constituyen tres diferentes tipos de pensamiento que entran en resonancia los unos con los otros.

No es este el lugar para extendernos sobre el tema de los tres tipos de creación de pensamiento (filosofía, arte, ciencia) y la compleja relación que se establece entre ellos. Lo que nos interesa por ahora, desde la perspectiva de una especie de "génesis", es la calidad "liminar", diríase embrionaria, del pensamiento como "natalidad": ese misterioso estadio que media entre el caos y la ya concluida determinación conceptual (en el caso de la filosofía). Y, como decíamos líneas arriba, es la crisis del sentido común, el encuentro con el signo-en-el-afuera el que permite ese sumergimiento en el caos como principio de una aventura del pensar y el planteamiento del problema que este supone. Para Deleuze y Guattari, el pensamiento traza, desde esa experiencia peligrosa y caotizante (es decir, el pensador estaría evitando la protección respecto del caos que permite la doxa), un "plano de inmanencia", cedazo o tamiz que "secciona la variabilidad caótica y le da consistencia (realidad)" 243 y que funciona como tierra pre-conceptual o pre-filosófica a ser poblada de conceptos. Cada cedazo es diferente y se superpone a otros, formando todos los planos un hojaldre, una estratigrafía del pensamiento y de la filosofía ${ }^{244}$. Los personajes conceptuales (el Sócrates de Platón, el Idiota de Descartes, el Zarathustra de Nietzsche), propiamente filosóficos, surgirían desde este plano, al igual que los conceptos que vendrían a poblarlo, todos en movimiento y en una relación permeable con el caos, con el infinito. Surge así el caos-cosmos o "caosmos", el acontecimiento de la filosofía o la filosofía como acontecimiento ${ }^{245}$.

242 Cf. Deleuze, G., ¿Qué es la filosofía?, Barcelona: Anagrama, 1993, pp. 202-220.

243 Ibid., p. 209.

244 “(...) el tiempo filosófico es un tiempo grandioso de coexistencia, que no excluye el antes y el después, sino que los superpone en un orden estratigráfico (...)” (ibid., pp. 60-6I).

245 Cf. ibid., pp. 46, 212. 
Si el problema y la pregunta solo son posibles gracias al plano de inmanencia, se podría decir que este "planómeno" secciona, en el caos, desde el movimiento de un "personaje conceptual" -especie de "operador" dentro del constructivismo filosófico. Así, el personaje conceptual es el intercesor del filósofo, el que ejecuta los movimientos que describen el plano de inmanencia e intervienen en la creación de los conceptos, las preguntas o el problema; por ejemplo, el "Idiota” de Descartes y la creación del concepto "Cogito"246. Este es pues un constructivismo filosófico que necesita ese piso pre-filosófico que otorga totalidad y consistencia, y que es establecido por el pensamiento luego de haber experimentado la peligrosa experiencia caotizante-esta última, una experiencia, según Deleuze y Guattari, del orden del inconsciente, del sueño, del exceso, que significa desprenderse del escudo empobrecedor de la opinión y sumergirse en el caos como condición de creación ${ }^{247}$.

Sin embargo, esta breve introducción a la naturaleza de la filosofía según Deleuze, estaría incompleta si es que no mencionáramos su tarea. Retomando lo dicho por Nietzsche, el filósofo debe hacer un diagnóstico, como un médico. Deleuze hará suya esa definición: el filósofo debe ser sintomatólogo, fisiólogo ${ }^{248}$. ¿Cuáles son los problemas que son importantes ahora? La importancia reside, en ese sentido, en la resonancia entre el arte y la filosofía: $L a$ imagen-movimiento y La imagen-tiempo, como estudios filosóficos del cine, se constituyeron como un diagnóstico del mundo moderno, pero un diagnóstico clínico, es decir, propiamente fisiológico a partir de los estados del cuerpo y del cerebro que los signos de espacio-tiempos del cine suponen y moldean. Precisamente por eso, a Deleuze le interesaba que, en el paso a la modernidad del cine, el tiempo se liberaba de su subordinación al movimiento o la acción y se nos daba una presentación pura del tiempo, una crisis del tiempo. Pero el diagnóstico no era meramente formal: del cine clásico al cine moderno, se rompían los lazos que unían al hombre con el mundo. Hemos dejado de creer en el mundo $y$, sin embargo, tenemos que creer ${ }^{249}$. Nos vemos ante la imposibilidad/posibilidad de creer en el mundo. ¿Por qué ya no se cree en el

246 Cf. ibid., pp. 63-85.

247 Cf. ibid., p. 46.

248 Cf. Deleuze, G., Nietzsche, Madrid: Arena, 2000, pp. 23-24.

249 "El hombre (...) se halla en la situación psíquica del vidente, que ve tanto mejor y más lejos cuanto que no puede reaccionar, es decir, pensar. ¿Cuál es entonces la sutil salida? Creer, no en otro mundo sino en el vínculo del hombre con el mundo, en el amor o en la vida, creer en ello 
mundo? ¿Por la proliferación de clichés, por el fracaso de las revoluciones, porque hay demasiada comunicación?

En efecto, sea cual sea la razón, el hombre de La imagen-tiempo se enfrentaba a su imposibilidad de creer, se enfrentaba a su asfixia como una "momia" que se retira de la vida. Se enfrentaba a la suspensión de su creencia. Dice Deleuze que esto es peor que perder a un Dios o a una novia. Se trata de perder el mundo ${ }^{250}$. Frente a esa pérdida del vínculo con el mundo, experimentamos, de acuerdo a los libros filosóficos sobre el cine, la pura potencia/impotencia del pensamiento, impotencia del hombre que, ahora, se relaciona con el mundo en la forma de una creencia. La posibilidad de la creencia (en el mundo) como modo de existencia es la pregunta fundamental para Deleuze al final de su vida.

\section{§ 3. Agamben}

Entonces llegamos a Agamben, que toma la posta de Deleuze. De Heidegger, retoma una profunda capacidad de creación conceptual a partir del estudio del lenguaje y de la efectuación de la Historia en el uso o invención de las palabras. Pero si Agamben es, sobre todo, deleuziano, es porque parte, como él, de Spinoza, un filósofo de la potencia que piensa la vida desde la potencia del cuerpo.

A este punto de partida debemos agregar una inspiración también focaultiana. Agamben, desde Homo sacer, estudia no solo lo que, históricamente, hace el poder con el cuerpo o cómo este se define en relación al derecho que crea sobre el cuerpo. En función a este proceder "genealógico", Agamben hace su filosofía sobre el saber que este derecho sobre el cuerpo supone. En ese sentido, crea el concepto de "nuda vida", vida desnuda, vida como "zoé", como pura potencia más allá de lo que determina la ley del Estado como lo propiamente "humano" o "ciudadano"251 -caracteres presupuestos como efectuación o producción que no solo prevé el poder, o que demanda el poder,

como en lo imposible, lo impensable, que sin embargo no puede sino ser pensado: 'posible, o me ahogo"' (Deleuze, G., La imagen-tiempo. Estudios sobre cine 2, p. 227).

250 Cf. ibid., pp. 227-23I; Deleuze, G., ¿Qué es la filosofía?, p. 76.

$25 I$ Cf. Agamben, G., Homo sacer. El poder soberano y la nuda vida, Valencia: Pre-Textos, 2010, pp. I5I-|8I. 
sino también el capital. Agamben, así, desarrolla una filosofía de la vida y de la íntima formación de la ley y los Estados modernos en su conceptualización de la vida. Para ello, también, recurre a Aristóteles, quien distinguía entre phoné (voz) y logos (lenguaje), como una distinción equivalente entre "nuda vida", por un lado, y vida política o ciudadana, por otro 252 .

Es así que asistimos a la invención instrumental de lo humano y a lo "humano" como categorización que se desgaja de la vida y de su intrínseca libertad como (im)potencia, pura voz sin lenguaje. ¿Podemos la voz sin el lenguaje? ¿Podemos la propia impotencia? ¿Qué significa eso, poder la propia impotencia? Esa es la fórmula que Agamben desarrolla en una rica invención de una propia filosofía de la vida. Pero también es una fórmula que ya se podía entrever en el ensayo de Deleuze sobre el amanuense "Bartleby" de Melville. Este relato del autor de Moby Dick trata del escribiente, del burócrata que se niega a realizar su labor, pero se niega con la sutil frase "preferiría no hacerlo" ("I would prefer not to"). En su libro Crítica y clínica, dice sobre él Deleuze: "Bartleby ha ganado el derecho a sobrevivir, es decir a mantenerse inmóvil y de pie frente a una pared ciega. Pura pasividad paciente (...). Ser en tanto que ser y nada más. Se le insta a decir sí o no. Pero si dijera no (cotejar copias, hacer recados...), si dijera sí (copiar), resultaría vencido enseguida, sería considerado inútil, no sobreviviría. Solo puede sobrevivir dando vueltas en un suspense que mantiene a todo el mundo alejado. Su medio de sobrevivencia consiste en preferir no cotejar las copias, pero debido a ello a la vez también en no preferir copiar. Tenía que rechazar una de las dos cosas para hacer imposible la otra" ${ }^{253}$. Habría que ver, en este elegante y misterioso gesto de Bartleby, un gesto revolucionario. Como dice Deleuze, para Bartleby se trata de "preferir nada antes que algo: no una voluntad de nada, sino el crecimiento de una nada de voluntad" 254 . Se trata de un gesto ético también el de este insignificante héroe moderno, ya que Bartleby es también ese ciudadano anónimo y gris que pareciera desaparecer de todo espectáculo, de todo campo de visión, de todo protagonismo histórico. Sin embargo, es el portador de un gesto ético supremo: el querer la propia impotencia.

252 Cf. ibid., p. 17.

253 Deleuze, G., Crítica y clínica, Barcelona: Anagrama, 1996, p. 102. 
Como hemos visto, Agamben va a querer desarrollar todas las implicancias de esta ruta filosófica, la ruta cuyo precursor fue Blanchot y que fue continuada por Deleuze y Foucault. Así, desde el concepto de vida como (im)potencia, va a extraer una ontología, va a practicar una genealogía del lenguaje, va a construir un doble histórico del derecho y va a postular una ética desde la deconstrucción de la biopolítica de Occidente. La ética de Agamben será la de afirmar la existencia como impotencia: "Hay, de hecho, alguna cosa que el hombre es y tiene que pensar, pero esto no es una esencia, ni es tampoco propiamente una cosa: es el simple hecho de la propia existencia como posibilidad y potencia" 255 .

Se trata de un postulado ético en tanto que es negativo para el capitalismo y para el derecho de la sociedad contemporánea y, más aun y de forma más directa, es negativo para el Poder del Estado y del Mercado, para una sociedad de control y de hiperconsumo, para una sociedad de hiperproducción, para una sociedad del espectáculo. Control, hiperproducción, hiperconsumo e hiperespectáculo están hermanados en un tramado de poder que se rebela frente a la que ahora pasa a ser la más suprema libertad: la de la impotencia. Quizá la nuda vida como (im)potencia sea el mayor peligro para esa trama de control e hiperproducción que, con Heidegger, era otra forma de nombrar el nihilismo como reino de la técnica moderna.

Así, por fin podemos cerrar el círculo y retomar la columna vertebral de nuestra exposición. La nuda vida, la vida como impotencia de Deleuze a Agamben es lo que puede y debe enfrentarse al nihilismo de la técnica. Heidegger, en ese sentido, necesitaba a Spinoza y a los hijos de Spinoza: Deleuze y Agamben en primer lugar. La presencia del árbol en flor, la película moderna de Heidegger, no solo reclamaba una re-incorporación como un salto hacia la finitud, hacia el acontecimiento como ruina de la re-presentación. También reclamaba, en esa re-incorporación, una existencia como potencia, como poder de la impotencia.

En ese sentido, terminamos y volvemos al tema de la (im)potencia del pensamiento. ¿Cómo se engendra el pensamiento en Agamben? ¿Cómo entender su "genitalidad"? Simplemente: en Agamben, a diferencia de Deleuze, el

255 Agamben, G., La comunidad que viene, Valencia: Pre-Textos, 2006, p. 4I. 
pensamiento ya no tiene que ser engendrado. El suyo también es un pensamiento de la inmanencia radical, pero toda su ontología y su ética, más que remitirse a un constructivismo o creacionismo, como en Deleuze, remite a la libertad y plenitud de la vida en tanto no actualizada, en tanto no definida, en tanto no identificable, en tanto no "humana" ni efectuada, en tanto ilimitada. En ese sentido es que podemos decir, también, que Agamben hace su filosofía desde donde Deleuze dejó la suya, y sobre todo si tenemos en cuenta el ensayo que Deleuze dejó poco antes de morir, titulado "La inmanencia: una vida (...)" (al que Agamben le dedica un capítulo en su libro La potencia del pensamiento).

Si en Deleuze la vida se estructuraba en el par virtual-actual, en torno a una multiplicidad creadora, en una filosofía de los encuentros y los devenires, en Agamben la vida como "nuda vida" es, como en Heidegger fue el "Ser", el concepto que nos debe obligar a releer la Historia, a decodificar el derecho y la política de Estado, en fin, a redefinir nuestra relación con nosotros mismos. Y, en ese sentido, en Agamben el "pensamiento" y la "filosofía" se remiten el uno al otro, como en Heidegger. Si la filosofía es un estudio de la coerción de la ley y el derecho -de cualquier índole- como consecuencia de una negación de la "nuda vida", o de la vida como pura (im)potencia, el "pensamiento", como diferente a la "filosofía", tiene su acabamiento o suprema positividad en sí mismo como (im)potencia, como doble condición de potente e impotente, como tabula rasa, como fruición anfibia en sí misma, pensamiento como poder de sí mismo en tanto ilimitado precisamente por no efectuado, por no constreñido a cumplir una función. El pensamiento, entonces, ya no debe ser engendrado, solo debe insistir en su propio vitalismo y plenitud que significa como (im)potencia. Es decir, la potencia, tanto para el cuerpo como para el pensamiento, en Agamben, es una experiencia de la privación y es esa experiencia de la privación la que distingue al hombre de los animales, en tanto que lo enfrenta a lo ilimitado de su poder, a lo abismal de su poder-no: "Los otros vivientes pueden solo su potencia específica, pueden solo este o aquel comportamiento inscrito en su vocación biológica; el hombre es el animal que puede la propia impotencia. La grandeza de su potencia se mide por el abismo de su impotencia"256. 


\section{§ 4. Conclusión}

Hemos querido, entonces, sugerir un estudio que permita hacer ver lo más original de tres filosofías desde el tema de la genitalidad e (im)potencia del pensamiento. Y esto supuso, pues, diferenciar al "pensamiento" del "ejercicio filosófico". La pregunta por la posibilidad de pensar remite a otra, a la pregunta por la filosofía, y viceversa.

Esta ambigüedad, en Heidegger, se decanta hacia la posibilidad del pensar en la experiencia del arte, tema que lo hermana con Deleuze. A ambos los hermana, también, la lucha contra la re-presentación y la maquinaria de la doxa (que serían las formas inferiores del pensamiento, si es que se puede llamar a este tipo de comunicación o razonamiento práctico, efectivamente, "pensamiento"). Luego, vimos cómo, en Deleuze, el pensamiento es una categoría crítica, un estado de crisis y de límite que hace, a su vez, posible la creación en arte, ciencia y filosofía.

Finalmente, Agamben retoma a Deleuze en cuanto a la positividad de la (im) potencia del pensamiento. Pero, en su caso, más allá de ser un punto de partida crítico que haría posible el comienzo de la creación, la (im)potencia es el fin a llegar, es en sí misma el más alto valor como pensamiento del pensamiento, como fruición de la privación y como estado de gracia de la vida como pura potencia, ilimitada y abismal. Así, desde una filosofía como genealogía, Agamben se enfrenta, más que con la re-presentación o la doxa (como en los casos de Heidegger y Deleuze), con la ley y el derecho en tanto puntos de partida para la justificación de poder sobre la vida y la muerte, sobre lo que para el Estado puede ser vida "humana" o "resto" de vida -vida que debe ser incluida o excluida, vivida o destruida. 